\title{
Uso de disacáridos y carbón activado para preservar consorcios de bacterias ruminales celulolíticas liofilizadas
}

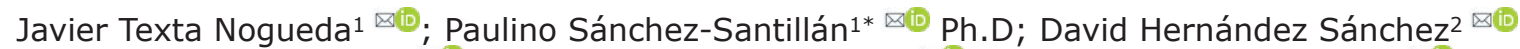

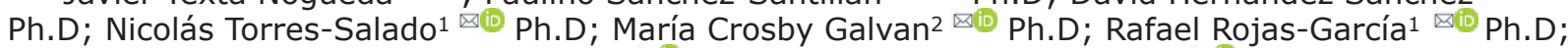 \\ Jerónimo Herrera-Pérez ${ }^{\otimes(\mathbb{0}}$ Ph.D; María Maldonado-Peralta ${ }^{\circledR}{ }^{\otimes}$ Ph.D.
}

1Universidad Autónoma de Guerrero, Facultad de Medicina Veterinaria y Zootecnia No. 2. Carretera Acapulco-Pinotepa Nacional Kilómetro 197, Cuajinicuilapa, Guerreo, México, C.P. 41940.

${ }^{2}$ Colegio de Postgraduados, Programa de Ganadería. Carretera México-Texcoco Km 36.5, Montecillos, Edo. De México, México, C.P. 56230. *Correspondencia: sanchezsantillanp@gmail.com

Recibido: Octubre 2018; Aceptado: Marzo 2019; Publicado: Agosto 2019.

\section{RESUMEN}

Objetivo. Determinar la fermentación in vitro de consorcios bacterianos ruminales celulolíticos (CBC) conservados por liofilización usando carbón activado, maltosa y lactosa como preservadores. Materiales y métodos. Un CBC se aisló de fluido ruminal de una búfala de agua en medios selectivos celulolíticos. Los CBC se liofilizaron con carbón activado (CA), lactosa (LA) o maltosa (MA) como preservadores y sin preservador (SP). El diseño experimental fue completamente al azar para medir biogás a diferentes intervalos de tiempo; así como, un diseño completamente al azar con arreglo factorial $4 \times 3$, los factores fueron preservadores (SP, CA, LA y MA) y tiempo de fermentación ( 24,48 y $72 \mathrm{~h}$ ) para $\mathrm{pH}$, nitrógeno amoniacal $\left(\mathrm{N}^{-} \mathrm{NH}_{3}\right)$, degradación de materia seca (DMS) y de fibra detergente neutro (DFDN), actividad enzimática celulasas y la población de bacterias totales. Resultados. LA produjo mayor biogás acumulado a las $72 \mathrm{~h}$ y parcial a partir de las $12 \mathrm{~h}(\mathrm{p} \leq 0.05)$. SP no mostró diferencias $(p>0.05)$ en celulasas, conteo de bacterias total, DMS y DFDN en los tiempos de fermentación evaluados con el resto de los preservadores. Conclusiones. La producción de biogás parcial y acumulada, el aumento en la tasa de degradación de 8.3 y $91.1 \%$ en la DMS y DFDN de las 24 a $72 \mathrm{~h}(\mathrm{p} \leq 0.05)$ con el preservador $L A$, muestran que la lactosa puede usarse como preservador de bacterias celulolíticas ruminales.

Palabras clave: Fermentación in vitro, lactosa, liofilización, maltosa, preservadores (Fuente: DeCS).

\section{ABSTRACT}

Objective. To determine in vitro fermentation of cellulolytic ruminal bacterial consortia (CBC) preserved by lyophilization using activated carbon, maltose and lactose as preservatives. Materials and methods. A CBC was isolated from the ruminal fluid of a female water buffalo in selective cellulolytic media. The CBC were lyophilized without preservative (SP), activated carbon (CA), lactose (LA) o maltose (MA) as preservatives. The experimental design was completely random to measure biogas at different time intervals; as well as completely random with $4 \times 3$ factorial arrangement, factors were preservative [SP, CA, LA and MA] and fermentation time $(24,48$ and $72 \mathrm{~h})$ for $\mathrm{pH}$, ammoniacal nitrogen $\left(\mathrm{NH}_{3}-\mathrm{N}\right)$, dry matter degradation (DMD), neutral detergent fiber degradation (NDFD), enzymatic activity cellulases and total bacteria population. Results. LA produced higher accumulated biogas at $72 \mathrm{~h}$ and partial biogas after $12 \mathrm{~h}(\mathrm{p} \leq 0.05)$. SP did not show differences $(p>0.05)$ in cellulases, total bacteria population, DMD and NDFD in the fermentation times evaluated with the rest of the preservative. Conclusions. The production of partial and accumulated biogas, the increase in the degradation rate of 8.3 and $91.1 \%$ in the DMD and NDFD from 24 to $72 \mathrm{~h}(\mathrm{p} \leq 0.05)$ in the LA preservative, show that lactose can be used as a preservative of ruminal cellulolytic bacteria.

Keywords: In vitro fermentation, lactose, lyophilization maltose, preservatives (Source: DeCS).

Como citar (Vancouver).

Texta NJ, Sánchez-Santillán P, Hernández SD, Torres-Salado N, Crosby GM, Rojas-García R, et al. Uso de disacáridos y carbón activado para preservar consorcios de bacterias ruminales celulolíticas liofilizadas. Rev MVZ Cordoba. 2019; 24(3):7305-7313. DOI: https://doi.org/10.21897/rmvz.1412

(C)EI (los) autor (es), Revista MVZ Córdoba 2019. Este artículo se distribuye bajo los términos de la licencia internacional Creative Common Attribution 4.0 (https://creativecommons.org/licenses/by-sa/4.0/), que permite el uso sin restricciones, la distribución y la reproducción en cualquier medio, siempre que se otorgue el crédito apropiado al autor o autores originales y la fuente. 


\section{INTRODUCCIÓN}

Los microorganismos son fundamentales en los ciclos biogeoquímicos; su preservación son prioridad en los laboratorios de microbiología por el potencial biotecnológico que representan. Los recursos microbianos deben conservarse en buen estado fisiológico y genéticamente estables (1). Los principales métodos de conservación son crecimiento continuo, deshidratación y congelación. La liofilización es un proceso que sirve para la conservación y el transporte de productos biológicos, siendo un proceso importante en los campos de investigación (2). Sin embargo, durante el proceso puede presentarse desnaturalización de proteínas y daño del ADN por el choque osmótico y la lesión de membranas, disminuyendo la viabilidad celular (3). Por lo que se requiere de preservadores que reduzcan presión osmótica y estrés inducido por congelación y deshidratación; ya que, los microorganismos e incluso cepas de una especie determinada varían en su viabilidad después de la liofilización (2). Así, la información disponible sobre preservadores en la liofilización de microorganismos ruminales es escasa (4).

Los preservadores se clasifican en tres categorías: los que penetran tanto la pared celular como la membrana citoplasmática para que la membrana sea más plástica e impidan la formación de cristales de hielo dentro de la célula durante la congelación; los que penetran solo la pared celular para inducir plasmólisis de las células antes de la congelación; y los que no interactúan directamente con pared celular o membrana citoplasmática, pero que forman una capa viscosa que inhibe la tasa de crecimiento del hielo al aumentar la viscosidad de la solución (5).

Los azucares como preservadores actúan en las membranas celulares, ya que inhiben cambios de fase perjudiciales a baja hidratación, reduciendo las temperaturas de transición de gel a fase fluida (6). Por lo que los disacáridos se usan como preservadores porque estabilizan membranas lipídicas por la diferencia entre la temperatura de transición vítrea y la formación del estado vítreo del azúcar (2). Hubálek (7) reportó el usó de lactosa (1 al $10 \%$ ) como preservador en Lactococcus lactis, el cual mejoró la protección comparado con glicerina en cultivos almacenados a $-70^{\circ} \mathrm{C}$; además, publicó el uso de maltosa en combinación con glicerol para la conservación de Scenedesmus spp.

El carbón activado posee características de adsorción física reversible, adsorción en fase líquida sin eliminación por desorción simple y porosidad, lo que permite su uso como preservador de microorganismos (4). Sánchez-Santillán et al (4) usaron carbón activado en la conservación de consorcios bacterianos celulolíticos, el cual mejoró la degradación de celulosa cristalina comparado con aquellos que no contenían preservador.

En general, los estudios que involucran la conservación de microorganismos usando preservadores se basan en la viabilidad de estos al momento de la rehidratación, y algunos autores $(4,8,9,10)$ enfocan sus estudios en medir el efecto durante la fermentación de los microorganismos. Así, la hipótesis del presente estudio es que lactosa, maltosa y carbón activado sirven como preservadores de consorcios bacterianos celulolíticos, sin afectar su potencial durante la fermentación in vitro. Por tanto, el objetivo fue evaluar la fermentación in vitro de consorcios bacterianos ruminales celulolíticos conservados por liofilización usando carbón activado, maltosa y lactosa como preservadores.

\section{MATERIALES Y MÉTODOS}

Sitio de estudio. El trabajo se realizó en el Laboratorio de Nutrición Animal de la Facultad de Medicina Veterinaria y Zootecnia No. 2 de la Universidad Autónoma de Guerrero, ubicado en el municipio de Cuajinicuilapa, Guerrero, México. Geográficamente situado a $16^{\circ} 08^{\prime \prime}$ Latitud Norte y $98^{\circ} 23^{\prime \prime}$ de Longitud Oeste, a una altitud de 50 msnm, predominando un clima cálido subhúmedo con lluvias en verano y cálido subhúmedo con lluvias en verano, con precipitación media anual de $1,200 \mathrm{~mm}$ y una temperatura promedio anual de $25^{\circ} \mathrm{C}$ (11).

Aspectos éticos. La búfala de agua donante del fluido ruminal para la obtención de los consorcios bacterianos celulolíticos se manejó de acuerdo con el reglamento interno de bioética y bienestar de la Universidad Autónoma de Guerrero, según la norma oficial NOM-062-ZOO-1999 (12).

Medio de cultivo. El medio contenía $30 \mathrm{~mL}$ de fluido ruminal clarificado [líquido ruminal bovino fresco centrifugado $10 \mathrm{~min}$ a $12,857 \mathrm{x}$ g y esterilizado (All American ${ }^{\circledR}$ 1941X, USA) 15 min a $121^{\circ} \mathrm{C}$ y $\left.15 \mathrm{psi}\right], 5 \mathrm{~mL}$ de solución mineral I [ $6 \mathrm{~g} \mathrm{~K}_{2} \mathrm{HPO}_{4}$ (J. T. Baker ${ }^{\circledR}$ ) en $1000 \mathrm{~mL}$ de agua destilada], $5 \mathrm{~mL}$ de solución mineral II [ $6 \mathrm{~g} \mathrm{KH}_{2} \mathrm{PO}_{4}$ (J. T. Baker $\left.{ }^{\circledR}\right)+6 \mathrm{~g}\left(\mathrm{NH}_{4}\right)_{2} \mathrm{SO}_{4}$ (J. T. Baker $\left.{ }^{\circledR}\right)+$ $12 \mathrm{~g} \mathrm{NaCl}\left(\right.$ Meyer $\left.^{\circledR}\right)+2.45 \mathrm{~g} \mathrm{MgSO}_{4}\left(\right.$ Meyer $\left.^{\circledR}\right)+$ $1.6 \mathrm{~g} \mathrm{CaCl}-2 \mathrm{H}_{2} \mathrm{O}\left(\right.$ Meyer $\left.^{\circledR}\right)$ en $1000 \mathrm{~mL}$ de agua destilada], $0.1 \mathrm{~mL}$ de resarzurina a $0.1 \%$ (SigmaAldrich $\left.{ }^{\circledR}\right), 0.2 \mathrm{~g}$ de peptona de soya (MCD Lab $^{\circledR}$ ), $0.1 \mathrm{~g}$ de extracto de levadura (BD Bioxon ${ }^{\circledR}$ ), 2 $\mathrm{mL}$ de solución cisteína-sulfido $2.5 \mathrm{~g}$ L-cisteína (Sigma-Aldrich ${ }^{\circledR}$ ) en $15 \mathrm{~mL}$ de $2 \mathrm{~N} \mathrm{NaOH}$ (Meyer ${ }^{\circledR}$ ) $+2.5 \mathrm{~g}$ de $\mathrm{Na}_{2} \mathrm{~S}-9 \mathrm{H}_{2} \mathrm{O}\left(\right.$ Meyer $\left.^{\circledR}\right)$ aforado en 100 $\mathrm{mL}$ de agua destilada], $5 \mathrm{~mL}$ de solución a $8 \%$ de 
$\mathrm{Na}_{2} \mathrm{CO}_{3}$ (J. T. Baker ${ }^{\circledR}$ ) y $52.6 \mathrm{~mL}$ de agua destilada. El medio se esterilizó 15 min en autoclave a $121^{\circ} \mathrm{C}$ y 15 psi (4).

Consorcio bacteriano celulolítico. El fluido ruminal se obtuvo de una búfala de agua (Bubalus bubalis) mediante el uso de una sonda esofágica y se centrifugó 3 min a 1,157 x g (Metrix Velocity 14 , USA). Previo al muestreo la búfala (500 Kg PV) permaneció en una pradera de Pangola (Digitaria decumbes) con una edad de rebrote de $56 \mathrm{~d}$ antes de recolectar las muestras, sin recibir complemento alimenticio. El sobrenadante del fluido ruminal se recuperó y en condiciones de una campana de bioseguridad $\left(\right.$ Labconco $^{\circledR}$, USA) se utilizó como inóculo. Nueve $\mathrm{mL}$ de medio de cultivo estéril se agregaron a tubos de ensaye (Pirex ${ }^{\circledR}$, México; 18 x $150 \mathrm{~mm}$ ) que contenían $0.05 \mathrm{~g}$ de pasto mulato (Brachiaria híbrido CV. CIAT 36087) con 65 d de rebrote estéril, bajo flujo de $\mathrm{CO}_{2}$, y se mantuvieron $24 \mathrm{~h}$ a $39^{\circ} \mathrm{C}$ en una incubadora (Ecoshel 9082, México) para verificar esterilidad. A cada tubo, por triplicado se agregó $1 \mathrm{~mL}$ de inóculo y se incubó $72 \mathrm{~h}$ a $39^{\circ} \mathrm{C}$. Un $\mathrm{mL}$ de este medio inoculado se transfirió a otro tubo con medio y pasto estéril y se incubó $72 \mathrm{~h}$ a $39^{\circ} \mathrm{C}$. Cinco transferencias se realizaron para obtener el CBC.

Preservadores. En viales serológicos (60 mL) se depositaron $27 \mathrm{~mL}$ de medio de cultivo con celobiosa ( $0.1 \%$ de medio; Sigma-Aldrich $\left.{ }^{\circledR}\right)$ y carboximetilcelulosa ( $0.1 \%$ de medio; Meyer ${ }^{\circledR}$ ) estéril bajo flujo constante de $\mathrm{CO}_{2}$, y se mantuvieron $24 \mathrm{~h}$ a $39^{\circ} \mathrm{C}$ para detectar esterilidad. Los viales se inocularon con $3 \mathrm{~mL}$ del producto obtenido de la quinta transferencia y se incubaron $72 \mathrm{~h}$ a $39^{\circ} \mathrm{C}$. Los preservadores fueron: 1) SP, sin preservador, un vial inoculado como testigo; 2) CA, carbón activado como preservador, un vial inoculado con $1 \mathrm{~mL}$ de solución carbón activado (Hycel ${ }^{\circledR}$ ) $30 \%$ (p/v; $30 \mathrm{~g} 100 \mathrm{~mL}^{-1}$ agua destilada); 3) LA, lactosa como preservador, un vial inoculado con $1 \mathrm{~mL}$ de solución lactosa (Meyer ${ }^{\circledR}$ ) 30\% (p/v; $30 \mathrm{~g} 100 \mathrm{~mL}^{-1}$ agua destilada) y; 4) MA, maltosa como preservador, un vial inoculado con $1 \mathrm{~mL}$ de solución maltosa (Meyer $\left.{ }^{\circledR}\right) 30 \%$ (p/v; 30 g 100 $\mathrm{mL}^{-1}$ agua destilada). Los viales se inclinaron $25^{\circ}$ para ampliar la superficie de contacto durante la liofilización y se congelaron hasta alcanzar $-38^{\circ} \mathrm{C}$, luego se liofilizaron $\mathrm{a}-49^{\circ} \mathrm{C}$ y $0.420 \mathrm{mBar}$ por 24 h (Labconco ${ }^{\circledR}$ Freezone 6 L, USA).

Reactivación de los CBC. Nueve $\mathrm{mL}$ de medio de cultivo con celobiosa ( $0.1 \%$ ) y carboximetilcelulosa $(0.1 \%)$ estériles, se adicionaron con flujo de $\mathrm{CO}_{2}$ en tubos de ensaye estériles $(18 \times 150 \mathrm{~mm})$ y se incubaron $24 \mathrm{~h}$ para detectar esterilidad. Diez tubos se inocularon con $0.05 \mathrm{~g}$ de liofilizado de SP, CA, LA o MA, con flujo de $\mathrm{CO}_{2}$ y se incubaron $72 \mathrm{~h}$ a $39^{\circ} \mathrm{C}$. Posteriormente, en viales serológicos (120
$\mathrm{mL}$ ) estériles se agregaron $45 \mathrm{~mL}$ de medio de cultivo con celobiosa $(0.1 \%)$ y carboximetilcelulosa $(0.1 \%)$ estériles, con flujo de $\mathrm{CO}_{2}$ y se incubaron $24 \mathrm{~h}$ para detectar esterilidad. Estos se inocularon con $5 \mathrm{~mL}$ de un $C B C$ reactivado ( $S P, C A$, $L A$ o $M A$ ) y se incubaron $48 \mathrm{~h}$ a $39^{\circ} \mathrm{C}$ para producir el inóculo usado en la prueba de producción de gas in vitro.

Producción de gas in vitro. El sustrato fue pasto mulato que se cosechó a los 63 d de rebrote y se deshidrató a $60^{\circ} \mathrm{C}$ hasta peso constante en una estufa (Felisa ${ }^{\circledR}$ FE-293A, México). El tamaño de partícula se redujo en un molino Thomas-Wiley Mill (Thomas Scientific ${ }^{\circledR}$, Swedesboro, NJ, USA) con criba de $1 \mathrm{~mm}$. En el sustrato se cuantificó proteína cruda (PC), cenizas (Ce) y materia orgánica (MO) según AOAC (13); además, fibra detergente neutro (FDN) y fibra detergente ácido (FDA) con la metodología de ANKOM Technology Method según Van Soest et al (14) (Tabla 1).

Tabla 1. Composición química proximal del pasto mulato en base seca

\begin{tabular}{lc}
\hline \multicolumn{1}{c}{ Componentes } & Porcentaje \\
\hline Proteína cruda & 5.82 \\
Fibra detergente neutro & 75.42 \\
Fibra detergente ácido & 45.65 \\
Cenizas & 9.87 \\
Lignina detergente ácido & 5.52 \\
Hemicelulosa & 29.77 \\
Celulosa & 40.13 \\
\hline
\end{tabular}

El biodigestor fue un vial serológico de vidrio (120 $\mathrm{mL}$ ) con $0.5 \mathrm{~g}$ de pasto mulato y $45 \mathrm{~mL}$ de medio de cultivo. Los biodigestores se mantuvieron en condiciones anaeróbicas con $\mathrm{CO}_{2}$, se sellaron herméticamente con un tapón de neopreno (20 $\mathrm{mm} \varnothing$ ) y con un arillo de aluminio. Después, estos se esterilizaron $15 \mathrm{~min}$ a $121^{\circ} \mathrm{C}$ y $15 \mathrm{psi}$, y se incubaron $24 \mathrm{~h}$ a $39^{\circ} \mathrm{C}$ para verificar esterilidad (15). Los biodigestores se inocularon con SP, LA, MA O CA (10 repeticiones independientes) y se incubaron $72 \mathrm{~h}$ a $39^{\circ} \mathrm{C}$. La producción de biogás se midió a las $6,12,24,48$ y 72 h de incubación (16), mediante el desplazamiento del émbolo de una jeringa de vidrio (50 mL; BD Yale ${ }^{\circledR}$, Brasil). Además, a las 24, 48 y $72 \mathrm{~h}$ de incubación se registró pH y se cuantificó bacterias totales, nitrógeno amoniacal, actividad celulasas, degradación de materia seca y degradación de fibra detergente neutro.

pH. El pH del medio se registró con un potenciómetro (Hanna ${ }^{\circledR}$ HI2211, Italia; calibración: pH 7 y 4).

Conteo de bacterias totales. Un $\mathrm{mL}$ del medio obtenido de la parte media del biodigestor se mezcló con $0.25 \mathrm{~mL}$ de formaldehido (SigmaAldrich $^{\circledR}$ ) al $10 \%$ en un tubo de ensayo. La cantidad de bacterias totales se calculó por conteo directo en una cámara Petroff-Hausser $(4,15)$. 
Nitrógeno amoniacal $\left(\mathbf{N}-\mathbf{N H}_{3}\right)$. Un $\mathrm{mL}$ del medio contenido en el biodigestor se mezcló con $0.25 \mathrm{~mL}$ de ácido metafosfórico (Meyer ${ }^{\circledR}$ ) al $25 \%$ (proporción 4:1), la mezcla se centrifugó 25 min a $3,500 \times \mathrm{g}$ y el sobrenadante se recuperó en viales de $2 \mathrm{~mL}$. Un volumen de $20 \mu \mathrm{L}$ del sobrenadante se mezcló con $1 \mathrm{~mL}$ de solución fenol [10 mg de $\mathrm{Na}_{2}\left[\mathrm{Fe}(\mathrm{CN})_{5} \mathrm{NO}\right] * 2 \mathrm{H}_{2} \mathrm{O}\left(\right.$ Meyer $\left.^{\circledR}\right)+10 \mathrm{~g}$ de cristales de fenol (Meyer ${ }^{\circledR}$ ) aforado en $1000 \mathrm{~mL}$ de agua destilada] y $1 \mathrm{~mL}$ de solución de hipoclorito [7.5 g de $\mathrm{NaOH}\left(\right.$ Reasol $\left.{ }^{\circledR}\right)+21.3 \mathrm{~g} \mathrm{de} \mathrm{Na}_{2} \mathrm{HPO}_{4}$ (Meyer ${ }^{\circledR}$ ) $+15 \mathrm{~mL}$ de hipoclorito (5\%; Reasol ${ }^{\circledR}$ ), aforado a $1000 \mathrm{~mL}$ con agua destilada]. La mezcla se incubó 30 min a $37^{\circ} \mathrm{C}$ en baño María. Posteriormente, 5 $\mathrm{mL}$ de agua destilada se adicionaron para diluir la muestra y se mezcló con un agitador tipo vórtex (Genie 2 G-560, USA). La absorbancia se midió a $630 \mathrm{~nm}$ en un espectrofotómetro UV-VIS (Jenway ${ }^{\circledR}$ 6850 , USA) calibrado con un método $\left(r^{2}=0.9994\right)$ de concentración de nitrógeno amoniacal según McCullough (17).

Actividad enzimática de celulasas. Esta se midió con la concentración de azúcares reductores con el método del DNS (18). Dos $\mathrm{mL}$ del medio de cultivo se centrifugaron por $25 \min$ a 9,710 $x$ $\mathrm{g}$ y $4^{\circ} \mathrm{C}$ y el sobrenadante se usó como extracto enzimático. El sustrato fue carboximetilcelulosa (Meyer ${ }^{\circledR}$ ) al $0.5 \%$ (2.5 g de carboximetilcelulosa en $500 \mathrm{~mL}$ de amortiguador de citratos $50 \mathrm{mM}$ y $\mathrm{pH}$ 4.8). La curva estándar se preparó con una solución de glucosa $10 \mathrm{mM}[0.18 \mathrm{~g}$ de dextrosa $\left(\right.$ Merk $\left.{ }^{\circledR}\right) 100 \mathrm{~mL}^{-1}$ de amortiguador de citratos 50 $\mathrm{mM}$ y pH 4.8] $\left(r^{2}=0.9994\right)$. La mezcla de reacción para cada muestra contenía $1.8 \mathrm{~mL}$ de sustrato y $0.2 \mathrm{~mL}$ de extracto enzimático. La incubación fue en tubos de ensayo por duplicado por $60 \mathrm{~min}$ a $50^{\circ} \mathrm{C}$, se agregaron $3 \mathrm{~mL}$ de DNS y las muestras se hirvieron 5 min e inmediatamente se enfriaron en un recipiente con hielo y la absorbancia se midió a $540 \mathrm{~nm}$. Un blanco se preparó para cada muestra con $1.8 \mathrm{~mL}$ de sustrato, se incubó $60 \mathrm{~min}$ a $50^{\circ} \mathrm{C}$, se agregaron $3 \mathrm{~mL}$ de DNS y $0.2 \mathrm{~mL}$ de extracto enzimático, se hirvió por 5 min, se depositó en un recipiente con hielo y la absorbancia se midió a 540 $\mathrm{nm}$. La unidad (U) se definió como la cantidad de enzima que libera $1 \mu \mathrm{mol} \mathrm{min}{ }^{-1}$ de glucosa en las condiciones de reacción mencionadas.

Degradación de la materia seca (DMS) y de la fibra detergente neutro (DFDN). La muestra residual del biodigestor se filtró en bolsas ANKOM $^{\circledR}$ 541 con peso constante y la humedad se eliminó a $60^{\circ} \mathrm{C}$ por $24 \mathrm{~h}$ en un horno de secado. La DMS se calculó con la formula DMS $(\%)=$ (muestra inicial - muestra residual / muestra inicial) $* 100$ (16). Las bolsas ANKOM ${ }^{\circledR}$ se sellaron con calor y se determinó el contenido de FDN (14). El porcentaje de degradación de la FDN (\% DFDN) se calculó con la formula DFDN $(\%)=($ FDN inicial - FDN residual / FDN inicial) $* 100(16)$.

Análisis de resultados. Para la producción de biogás parcial a las $6,12,24,48$ y 72 h, y producción acumulada a las $72 \mathrm{~h}$ (10 muestras independientes) se usó un diseño completamente al azar. Las medias se compararon con la prueba de Tukey $(p \leq 0.05)$. El modelo estadístico utilizado fue: $Y_{i j}=\mu+T_{i}+\varepsilon_{i j}$; donde: $Y_{i j}=$ Variable de respuesta en el i-ésimo preservador y j-ésima repetición; $\mu=$ Media general; $T_{i}=$ Efecto del i-ésimo preservador; $\varepsilon_{\mathrm{ij}}=$ Error aleatorio, el cual se distribuye normalmente con media 0 y varianza $\sigma^{2}$.

Para actividad enzimática de celulasas ( 3 muestras independientes), DMS, DFDN (6 muestras independientes), $\mathrm{N}-\mathrm{NH}_{3}$, conteo de bacterias ( 5 muestras independientes) y $\mathrm{pH}$ (10 muestras independientes) se usó un diseño completamente al azar con arreglo factorial $4 \times 3$, considerando como factores a los preservadores (SP, CA, LA y MA) y tiempo de fermentación (24, 48 y 72 h). Las medias se ajustaron por mínimos cuadrados usando el PROC LSMEANS de $\operatorname{SAS}^{\circledR}$ (19) y se compararon con la prueba de Tukey ajustada. El modelo estadístico fue $Y_{i j k}=\mu+A_{i}+B_{j}+A_{i j}+$ $\varepsilon_{i j k} ;$ donde $Y_{i j k}=$ variable de respuesta; $\mu=$ media general; $A_{i} \stackrel{1 j k}{=}$ efecto del factor preservador; $B_{j}$ $=$ efecto del factor tiempo de incubación; $A B_{i j}=$ efecto de la interacción entre preservador y tiempo de incubación; $\varepsilon_{\mathrm{ijk}}=$ error aleatorio.

\section{RESULTADOS}

El preservador LA produjo mayor biogás acumulado $(p \leq 0.05)$ a las $72 \mathrm{~h}$. La producción de biogás de LA y CA fue 31.9 y $16.8 \%$ superior $(p \leq 0.05)$ a SP (testigo). MA y SP no presentaron diferencias $(p>0.05)$ en la producción de biogás acumulada a las 72 h (Tabla 2). En la producción parcial, CA produjo mayor $(p \leq 0.05)$ biogás a las $6 h$, pero LA produjo mayor $(p \leq 0.05)$ biogás que el resto de los preservadores a partir de las $12 \mathrm{~h}$ (Tabla 2 ). LA aumentó 52.3 y $81.8 \%$ la producción de biogás a las 48 y $72 \mathrm{~h}(\mathrm{p} \leq 0.05)$, con respecto a SP; CA no fue diferente $(p>0.05)$ a SP a las 48 y $72 h$; mientras, MA aumentó $(p \leq 0.05) 19.4$ y $39.5 \%$ a las 48 y $72 \mathrm{~h}$ de incubación (Tabla 2).

Tabla 2. Producción de biogás ( $\left.\mathrm{mL} \mathrm{g}^{-1} \mathrm{MS}\right)$ a $72 \mathrm{~h}$ de incubación de pasto mulato usando consorcios de bacterias celulolíticas ruminales liofilizadas, con y sin disacáridos y carbón activado como preservadores

\begin{tabular}{|c|c|c|c|c|c|c|}
\hline \multirow{2}{*}{ Preservador } & \multicolumn{5}{|c|}{ Producción parcial de biogás ( $\mathbf{m L} \mathbf{g}^{-1}$ MS) } & \multirow{2}{*}{$\begin{array}{c}\text { Acumulado } \\
72 \mathrm{~h}\end{array}$} \\
\hline & $6 \mathrm{~h}$ & $12 \mathrm{~h}$ & $24 h$ & $48 h$ & $72 \mathrm{~h}$ & \\
\hline Sin preservador & $31.93^{c}$ & $11.17^{\mathrm{b}}$ & $11.52^{c}$ & $8.32^{c}$ & $7.04^{c}$ & $73.82^{c}$ \\
\hline Carbón activado & $44.46^{a}$ & $8.95^{c}$ & $13.48^{\mathrm{b}}$ & $8.21^{c}$ & $7.11^{c}$ & $86.20^{\mathrm{b}}$ \\
\hline Lactosa & $39.44^{\mathrm{b}}$ & $13.15^{\mathrm{a}}$ & $18.76^{a}$ & $12.67^{a}$ & $12.79^{a}$ & $97.41^{a}$ \\
\hline Maltosa & $19.85^{d}$ & $9.82^{\mathrm{bc}}$ & $13.95^{\mathrm{b}}$ & $9.93^{b}$ & $9.82^{\mathrm{b}}$ & $67.25^{c}$ \\
\hline EEM & 1.06 & 0.29 & 0.34 & 0.30 & 0.47 & 2.13 \\
\hline
\end{tabular}

$a, b, c$ Medias en una columna con distinta literal son diferentes $(p \leq 0.05)$. $\mathrm{EEM}=$ error estándar de la media. 
La tabla 3 muestra el valor de p de los factores principales y su interacción; ya que la fermentación in vitro se realizó a diferentes tiempos para ver los cambios conforme aumentaba el tiempo de fermentación (Tabla 4). El SP no mostró diferencias $(p>0.05)$ en la degradación de la materia seca en los tiempos de fermentación evaluados (Tabla 4). Todos los preservadores (SP, LA, MA y CA) no tuvieron diferencias $(p>0.05)$ en la DMS a las 72 $h$ de incubación. Los preservadores SP, CA, LA y MA no presentaron diferencias $(p>0.05)$ en la degradación de la FDN (DFDN) a las 24, 48 y 72 h (Tabla 4), promediando 3.7, 5.0 y $6.4 \%$ DFDN, respectivamente.

Tabla 3. Valor de $p$ de las características fermentativas a las 24,48 y $72 \mathrm{~h}$ de incubación con consorcios de bacterias celulolíticas ruminales liofilizadas con y sin lactosa, maltosa y carbón activado como preservadores

\begin{tabular}{lccc}
\hline \multicolumn{1}{c}{ Variable } & Preservador & Tiempo & $\begin{array}{c}\text { Preservador* } \\
\text { Tiempo }\end{array}$ \\
\hline $\begin{array}{l}\text { Celulasas } \\
\begin{array}{l}\text { Degradación de materia } \\
\text { seca }\end{array}\end{array}$ & 0.2946 & 0.0077 & 0.3645 \\
$\begin{array}{l}\text { Degradación de fibra } \\
\text { detergente neutro }\end{array}$ & 0.0001 & $<.0001$ & 0.0006 \\
$\begin{array}{l}\text { Nitrógeno Amoniacal } \\
\text { Bacteria }\end{array}$ & $<.0001$ & $<.0001$ & $<.0001$ \\
pH & 0.0033 & $<.0001$ & 0.1892 \\
\hline
\end{tabular}

Tabla 4. Nitrógeno amoniacal, degradación de la materia seca y de la fibra detergente neutro a las 24,48 y $72 \mathrm{~h}$ de incubación con consorcios de bacterias celulolíticas ruminales liofilizadas con y sin lactosa, maltosa y carbón activado como preservadores\&

\begin{tabular}{|c|c|c|c|c|}
\hline Preservador & $\begin{array}{l}\text { Tiempo de } \\
\text { fermentación }\end{array}$ & $\begin{array}{l}\text { DMS } \\
(\%)\end{array}$ & $\begin{array}{l}\text { DFDN } \\
(\%)\end{array}$ & $\underset{\left(\mathrm{mg} \mathrm{dL}^{-1}\right)}{\mathrm{N}-\mathrm{NH}_{3}}$ \\
\hline \multirow[t]{3}{*}{ Sin preservador } & $24 \mathrm{~h}$ & $24.61^{a}$ & $3.95^{\text {bcde }}$ & $18.39^{d}$ \\
\hline & $48 \mathrm{~h}$ & $25.49^{a}$ & $6.13^{\mathrm{abcd}}$ & $22.93^{b}$ \\
\hline & $72 \mathrm{~h}$ & $25.30^{a}$ & $7.47^{\mathrm{a}}$ & $22.69^{b}$ \\
\hline \multirow[t]{3}{*}{ Carbón activado } & $24 \mathrm{~h}$ & $22.84^{b}$ & $2.35^{\mathrm{e}}$ & $18.42^{\mathrm{d}}$ \\
\hline & $48 \mathrm{~h}$ & $25.12^{a}$ & $5.02^{\text {abcde }}$ & $19.05^{\mathrm{cd}}$ \\
\hline & $72 \mathrm{~h}$ & $25.08^{a}$ & $6.33^{\mathrm{abc}}$ & $20.22^{c}$ \\
\hline \multirow[t]{3}{*}{ Lactosa } & $24 \mathrm{~h}$ & $22.85^{b}$ & $3.49^{\text {cde }}$ & $18.81^{c d}$ \\
\hline & $48 \mathrm{~h}$ & $23.02^{b}$ & $3.32^{\mathrm{ed}}$ & $23.03^{b}$ \\
\hline & $72 \mathrm{~h}$ & $24.75^{a}$ & $6.67^{\mathrm{ab}}$ & $24.07^{a b}$ \\
\hline \multirow[t]{3}{*}{ Maltosa } & $24 \mathrm{~h}$ & $25.25^{a}$ & $4.86^{\mathrm{abcde}}$ & $19.70^{\mathrm{cd}}$ \\
\hline & $48 \mathrm{~h}$ & $25.17^{a}$ & $5.71^{\mathrm{abcd}}$ & $22.95^{b}$ \\
\hline & $72 \mathrm{~h}$ & $25.27^{a}$ & 5.19abcde & $24.89^{a}$ \\
\hline EEM & & 0.15 & 0.24 & 0.31 \\
\hline
\end{tabular}

\&Las variables presentaron interacción significativa preservador tiempo de incubación $(\mathrm{p} \leq 0.05)$.

$a, b, c, d, e$ Medias en una columna con distinta literal son diferentes $(p \leq 0.05)$. DMS=degradación de la materia seca; DFDN=degradación de la fibra detergente neutro; $\mathrm{N}-\mathrm{NH}_{3}$, nitrógeno amoniacal; EEM = error estándar de la media.

A las 24 h de incubación, todos los preservadores no presentaron diferencias $(p>0.05)$ en el contenido de $\mathrm{N}-\mathrm{NH}_{3}$ en los biodigestores (Tabla 4), promediando una concentración de $18.8 \mathrm{mg} \mathrm{dL}^{-1}$.
La concentración de $\mathrm{N}-\mathrm{NH}_{3}$ no presento diferencias $(p>0.05)$ entre las 48 y $72 \mathrm{~h}$ de los preservadores SP, CA y LA. Esta concentración representó un aumento ( $p \leq 0.05$ ) de $24.0,6.5$ y $25.19 \%$ respecto a las primeras $24 \mathrm{~h}$ de incubación de SP, CA y $L A$, respectivamente. Con $M A$, la concentración incremento $(p \leq 0.05)$ conforme aumento el tiempo de incubación.

La actividad enzimática de celulasas no mostró diferencias entre preservadores $(p>0.05)$, promediando $90.33 \mathrm{mU} \mathrm{mL}^{-1}$. En contraste, por tiempo de incubación, a las 24 h se observó $3.6 \%$ mayor $(p \leq 0.05)$ actividad celulasas que a las 48 h; mientras, a las $72 \mathrm{~h}$ la actividad no mostró diferencias $(p>0.05)$ con el resto de los tiempos de incubación (Tabla 5).

Table 5. Actividad enzimática celulasas, conteo total de bacterias y $\mathrm{pH}$ con consorcios de bacterias celulolíticas ruminales liofilizadas con y sin lactosa, maltosa y carbón activado como preservadores en diferentes tiempos de incubación\&

\begin{tabular}{|c|c|c|c|}
\hline Preservador & $\begin{array}{l}\text { Celulasas } \\
\left(\mathrm{mU} \mathrm{mL}^{-1}\right)\end{array}$ & $\begin{array}{c}\text { [B] } \\
\left(10^{9} \text { células } m L^{-1}\right)\end{array}$ & pH \\
\hline \multicolumn{4}{|c|}{ Preservador } \\
\hline Sin preservador & 91.17 & $5.37^{\mathrm{ab}}$ & $6.98^{\mathrm{a}}$ \\
\hline Carbón activado & 89.21 & $5.82^{\mathrm{a}}$ & $6.96^{\mathrm{a}}$ \\
\hline Lactosa & 90.89 & $6.02^{a}$ & $6.92^{b}$ \\
\hline Maltosa & 90.05 & $4.57^{b}$ & $6.94^{\mathrm{ab}}$ \\
\hline \multicolumn{4}{|c|}{ Tiempo de incubación } \\
\hline $24 \mathrm{~h}$ & $92.09^{a}$ & $1.96^{c}$ & $6.91^{\mathrm{b}}$ \\
\hline $48 \mathrm{~h}$ & $88.84^{b}$ & $5.23^{b}$ & $6.98^{a}$ \\
\hline $72 \mathrm{~h}$ & $90.06^{\mathrm{ab}}$ & $9.14^{a}$ & $6.96^{a}$ \\
\hline EEM & 0.45 & 0.41 & 0.01 \\
\hline
\end{tabular}

\&Las variables no presentaron interacción significativa preservador tiempo de incubación ( $p>0.05)$.

$a, b, c$ Medias en una columna con distinta literal son diferentes $(p \leq 0.05)$. Celulasas = actividad enzimática celulasas; $[\mathrm{B}]=$ conteo total de bacterias; EEM = error estándar de la media.

En el conteo total de bacterias, SP no presentó $(p>0.05)$ diferencias con los otros preservadores (Tabla 5). Sin embargo, dicho conteo aumento ( $p \leq 0.05$ ) $166.8 \%$ de las 24 a 48 h de incubación, así como $74.7 \%$ de las 48 a las 72 h ( $p \leq 0.05$; Tabla 5). Finalmente, el pH osciló entre 6.91 y 6.98, valores cercanos a la neutralidad sin diferencias entre preservadores (Tabla 5).

\section{DISCUSIÓN}

La preservación de microorganismos sirve en muchos campos de investigación y la consistencia genética es crucial para las bacterias utilizadas (3). La producción parcial de biogás indica cómo se fermentan los carbohidratos, ya que en las primeras $24 \mathrm{~h}$ se fermenta el contenido celular y a partir de las $24 \mathrm{~h}$ se fermentan los carbohidratos 
estructurales (15). Resultados superiores a los observados por todos los preservadores en el presente estudio fueron publicados por HerreraPérez et al (15); quienes reportaron una producción acumulada de $103.4 \mathrm{~mL} \mathrm{~g}^{-1} \mathrm{MS}$, en pasto cobra inoculado con un consorcio de bacterias celulolíticas de búfala de agua. Estos valores de producción de biogás se atribuyen a los nutrientes disponibles (20) en los pastos mulato y cobra, eficiencia de uso de los pastos por los microorganismos, al origen de los consorcios bacterianos celulolíticos ruminales y densidad de los microorganismos presentes (21).

Además, las diferencias en la producción de biogás parcial entre el SP y lo reportado por Herrera-Pérez et al $\left(15 ; 61.7,14.3,6.7,11.2\right.$ y $9.5 \mathrm{~mL} \mathrm{~g}^{-1} \mathrm{MS}$ a las $9,12,24,48$ y $72 \mathrm{~h}$, respectivamente) y los niveles de DMS de SP, se asume a que en este estudio son $\mathrm{CBC}$ reactivados después de una liofilización; ya que esta técnica puede dañar estructuras de la pared celular, la membrana celular y el ADN lo que generó una disminución de la viabilidad celular (3) cuando se reactivaron los CBC; mientras, HerreraPérez et al (15) usaron $\mathrm{CBC}$ sin liofilizar. Esto contrasta, si se comparan los datos de HerreraPérez et al (15) con el preservador LA, dado que la producción parcial de LA fue mayor a partir de las $24 \mathrm{~h}$, porque la lactosa estabiliza las membranas celulares debido a la diferencia en la temperatura de transición vítrea (2) e inhibe cambios de fase perjudiciales a baja hidratación (6).

Ninguno de los preservadores evaluados mejoró la capacidad de degradación de la materia seca (DMS), contrario a lo publicado por otros autores $(2,3,5,6,7,8)$, quienes mencionan que la adición de sustancias preservadoras protege a las bacterias durante la congelación y desecación del proceso de liofilización. Sin embargo, el uso de estos protectores solo se ha estudiado en cuanto a la viabilidad de las bacterias, sin reportes sobre sus efectos variables de la fermentación in vitro, como los reportados en el presente estudio. Así, LA aumentó ( $p \leq 0.05$ ) 8.3\% la DMS entre las 24 y 72 $h$ de incubación; mientras, CA aumentó $(p \leq 0.05)$ la DMS en $10.1 \%$ de las 24 a las 48 h de incubación. Esto es importante, porque a partir de las $24 \mathrm{~h}$ se da la fermentación de los carbohidratos estructurales (15) y en el presente estudio se evaluaron CBC, los que mejoraron la DMS a partir de las $24 \mathrm{~h}$ (Tabla 3 ). Resultados superiores a los preservadores $\mathrm{SP}, \mathrm{LA}, \mathrm{MA}, \mathrm{CA}$ a las $72 \mathrm{~h}$ fueron publicados por Herrera-Pérez et al (15) y Sánchez-Santillán et al (4), quienes reportaron $29.65 \%$ de DMS en pasto cobra inoculado con un CBC, $32.75 \%$ de DMS en papel Whatman ${ }^{\circledR}+$ celulosa cristalina inoculado con un CBC liofilizado con carbón activado como preservador. Esto se asume al origen y tipo de $C B C$, conformación de la población microbiana del CBC, especie donadora para la obtención de los CBC y la composición nutritiva del sustrato (20).
La lactosa, carbón activado y maltosa como preservadores en la liofilización de un CBC no mejora ni disminuye la DFDN cuando se reactiva el CBC para fermentar in vitro al pasto mulato. Sin embargo, la tasa de degradación de las 24 a las $72 \mathrm{~h}$ de incubación aumentó 6.7, 89.1, 91.1, $169.4 \%$ en los preservadores MA, SP, LA y CA, respectivamente. Resultados superiores fueron reportados por Herrera-Pérez et al (15) en pasto cobra $(10.67 \%)$ e inferiores en rastrojo de maíz (3.94\%) inoculados con un CBC obtenido de una búfala de agua. Los niveles de degradación de la materia seca y de la fibra detergente neutro por los CBC se atribuye a la necesidad de interactuar con otros microorganismos mediante alimentación cruzada $(4,15,22)$ y la capacidad de represión catabólica por la presencia de glucosa u otros compuestos en el medio que inhiben la síntesis enzimática $(15,23)$; ya que, al cultivarse con bacterias ruminales se mejoró la capacidad de degradación de los CBC (15).

Russell et al (24) y Carro et al (25) reportan que las bacterias celulolíticas utilizan como única fuente nitrogenada el nitrógeno amoniacal $\left(\mathrm{N}-\mathrm{NH}_{3}\right)$ y la concentración depende de la degradabilidad de las fracciones nitrogenadas que componen la dieta (26); al usar únicamente el pasto mulato, peptona de soya y extracto de levadura en los biodigestores, los niveles de $\mathrm{N}-\mathrm{NH}_{3}$ se asumen al comportamiento de los CBC (Tabla 4) durante las 72 h de incubación. De modo que, el uso de lactosa y maltosa como preservadores de los CBC no afectaron la concentración de $\mathrm{N}-\mathrm{NH}_{3}$ conforme aumento $(p \leq 0.05)$ el tiempo de incubación; en contraste, el carbón activado disminuyó la concentración. Cabe destacar, la concentración de $\mathrm{N}-\mathrm{NH}_{3}$ de todos los preservadores en los tiempos evaluados (Tabla 4) se mantiene dentro del rango reportado por Chandrasekharaiah et al (27). Resultados similares fueron reportados por Herrera-Pérez et al (15) y mayores a Chanthakhoun et al (28); quienes publicaron una concentración de $18.26 \mathrm{mg} \mathrm{dL}^{-1}$ en biodigestores que contenían pasto cobra inoculado con CBC obtenido de búfala de agua (15); y 14.7 $\mathrm{mg} \mathrm{dL}^{-1}$ en rumen de búfalos alimentados con paja de arroz y $0.3 \%$ del peso corporal de un concentrado (28).

La producción de enzimas celulasas y conteo total de bacterias por CBC liofilizados y reactivados no se afectó con el uso de lactosa, maltosa o carbón activado como preservador. Resultados superiores fueron reportados por Otajevwo y Aluyi (29) y Poszytek et al (9); quienes publicaron una actividad de $5.32 \mathrm{U} \mathrm{mL}^{-1}$ por Clostridium thermocellum incubadas a $37^{\circ} \mathrm{C}$ y pH de 7.2 (29); así como, 0.38 $\mathrm{U} \mathrm{mL} \mathrm{m}^{-1}$ por Providencia sp. incubada a $37^{\circ} \mathrm{C}$ por 24 h (9). Una explicación del bajo rendimiento de la celulasa en el presente estudio puede asumirse a las condiciones de fermentación anaerobia (29) porque la temperatura y $\mathrm{pH}$ son aspectos 
importantes en la hidrólisis de la celulosa y producción de celulasas (9), tipo y composición del sustrato del que preceden los CBC (29) y tiempo de incubación del método para determinar actividad enzimática (30).

El aumento de la población de bacterias estimada en los diferentes tiempos de incubación evaluados es por la proliferación de bacterias celulolíticas a partir de las $24 \mathrm{~h}$, las cuales fermentan los carbohidratos estructurales (15) y el inóculo usado en el presente estudio fue un CBC. Sin embargo, la población microbiana se contradice con la actividad de celulasas, pues no aumentó la cantidad de celulasas conforme aumentó la población de bacterias. El crecimiento de la población bacteriana en el presente estudio también se puede asumir a los valores de $\mathrm{pH}$ determinados, permitiéndoles un correcto funcionamiento, dado que en $\mathrm{pH}$ inferiores a 6.0 se inhibe su actividad enzimática $(15,10)$. Herrera-Pérez et al (15) publicaron valores similares en $\mathrm{pH}$ y conteos totales de bacterias inferiores al presente estudio, en pasto cobra y rastrojo de maíz inoculados con $\mathrm{CBC}$.

La lactosa puede usarse como preservador de consorcios bacterianos celulolíticos ruminales dados los resultados en producción parcial y acumulada de biogás, y el aumento en la tasa de degradación de la DMS y DFDN de las 24 a 72 h ( $p \leq 0.05)$, sin cambios en el contenido de $\mathrm{N}-\mathrm{NH}_{3}, \mathrm{pH}$ del medio y conteo total de bacterias respecto al CBC testigo. Sin embargo, la maltosa y el carbón activado como preservadores de consorcios bacterianos celulolíticos ruminales presentaron resultados positivos en ciertas variables de la fermentación in vitro comparado con los consorcios bacterianos celulolíticos que no se adicionó un preservador, lo que demanda mayores estudios sobre el uso de preservadores en bacterias celulolíticas ruminales.

\section{Conflicto de intereses.}

Los autores del presente estudio declaramos que no existe conflicto de intereses con la publicación de este manuscrito.

\section{Agradecimientos}

Al Consejo Nacional de Ciencia y Tecnología por el financiamiento del proyecto 253275 dentro de la convocatoria de Ciencia Básica CB-2015-01 "Elaboración de un probiótico a partir de bacterias celulolíticas aisladas de búfalos de agua y bovinos para mejorar la degradación in vitro de los principales forrajes usados en la alimentación de rumiantes".

\section{REFERENCIAS}

1. Morales-García YE, Duque E, RodríguezAndrade $\mathrm{O}$, de la Torre J, MartínezContreras RD, Pérez-y-Terrón R, y MuñozRojas J. Bacterias preservadas, una fuente importante de recursos biotecnológicos. Biotecnología. 2010; 14(02):11-29. https:// www.researchgate.net/profile/Jesus Munoz-Rojas/publication/235901617 Bacterias Preservadas una Fuente Importante de Recursos Biotecnologicos/ links/0912f513faa98c769b000000.pdf

2. Boge L, Västberg A, Umerska A, Bysell $H$, Eriksson J, Edwards $\mathrm{K}$, et al. Freeze-dried and re-hydrated liquid crystalline nanoparticles stabilized with disaccharides for drugdelivery of the plectasin derivative AP114 antimicrobial peptide. J Colloid Interface Sci. 2018; 522:126-135. DOI: https://doi. org/10.1016/j.jcis.2018.03.062
3. Krumnow AA, Sorokulova BI, Olsen E, Globa L, Barbaree MJ, and Vodyanoy JV. Preservation of bacteria in natural polymers. J Microbiol Methods. 2009; 78(2):189-194. DOI: https:// doi.org/10.1016/j.mimet.2009.05.017

4. Sánchez-Santillán $P$, Cobos-Peralta MA, Hernández-Sánchez D, Álvarado AI, EspinosaVictoria D, y Herrera-Haro JG. Use of activated carbon to preserve lyophilized cellulolytic bacteria. Agrociencia 2016; 50(5):575582. https://www.colpos.mx/agrocien/ Bimestral/2016/jul-ago/art-3.pdf

5. Carvalho AS, Silva J, Ho P, Teixeira P, Malcata FX, and Gibbs P. Effects of Various Sugars Added to Growth and Drying Media upon Thermotolerance and Survival throughout Storage of Freeze-Dried Lactobacillus delbrueckii ssp. Bulgaricus. Biotechnol. 2004; 14(10): 248-254. DOI: https://doi. org/10.1016/j.idairyj.2004.02.001 
6. Lenne T, Bryanta G, Garveyb CJ, Keiderlingc U, Kosterd KL. Location of sugars in multilamellar membranes at low hydration. Physica B. 2006; 385-386(2):862-864. DOI: https:// doi.org/10.1016/j.physb.2006.05.127

7. Hubalek Z. Protectants used in the cryopreservation of microorganisms. Cryobiology. 2003; 46(3):205-229. DOI: https://doi.org/10.1016/S00112240(03)00046-4

8. Lu Y, Huang L, Yang T, Lv F, Lu Z. Optimization of a cryoprotective medium to increase the viability of freeze-dried Streptococcus thermophilus by response surface methodology. Food Sci Technol. 2017; 80:92-97. DOI: http://dx.doi. org/10.1016/j.Iwt.2017.01.044

9. Poszytek K, Ciezkowska M, Sklodowska A, Drewniak L. Microbial consortium with high cellulolytic activity (mchca) for enhanced biogas production. Front Microbiol. 2016; 7:324-334. DOI: https://doi.org/10.3389/ fmicb.2016.00324

10. Sánchez-Santillán $P$, Cobos-Peralta MA. In vitro production of volatile fatty acids by reactivated cellulolytic bacteria and total ruminal bacteria in cellulosic substrate. Agrociencia. 2016; 50(5):565-574. https:// www.colpos.mx/agrocien/Bimestral/2016/ jul-ago/art-2.pdf

11. INEGI. Anuario estadístico y geográfico de los Estados Unidos Mexicanos. Instituto Nacional de Estadística Geografía e Informática. (Acceso el 01 de octubre de 2018). URL disponible en www.beta.inegi.org.mx/app/ areasgeograficas/?ag $=12023$

12. NOM-062-ZOO-1999. Norma Oficial Mexicana, Especificaciones técnicas para la producción, cuidado y uso de los animales de laboratorio. Servicio Nacional de Sanidad, Inocuidad y Calidad Agroalimentaria. SENASICA, México. 22 de agosto de 2001. URL disponible en https://www.gob.mx/cms/ uploads/attachment/file/203498/NOM-062ZOO-1999 220801.pdf.

13. AOAC. Official Methods of Analysis (19th) Association of official Analytical Chemist. Arlington (VA), Washington DC: AOAC; 2012. http://www.aoac.org/aoac prod imis/ AOAC Docs/OMA/OMA19Revisions.pdf
14. Van Soest PJ, Robertson JB, Lewis BA. Methods for dietary fiber, neutral detergent fiber and nonstarch polysaccharides in relation to animal nutrition. J Dairy Sci. 1991; 74(10):3583-3597. https://doi.org/10.3168/ jds.S0022-0302(91)78551-2

15. Herrera-Pérez J, Vélez-Regino L, SánchezSantillán P, Torres-Salado N, Rojas-García A, Maldonado-Peralta M. In vitro fermentation of fibrous substrates by wáter buffalo ruminal cellulolytic bacteria consortia. Rev MVZ Córdoba. 2018; 23(3):6860-6870. DOI: https://doi.org/10.21897/rmvz.1374

16. Hernández-Morales J, Sánchez-Santillán $P$, Torres-Salado N, Herrera-Pérez J, RojasGarcía AR, Reyes-Vázquez I, Mendoza-Núñez MA. Composición química y degradaciones in vitro de vainas y hojas de leguminosas arbóreas del trópico seco de México. Rev Mex Cienc Pecu. 2018; 9(1):105-120. DOI: http:// dx.doi.org/10.22319/rmcp.v9i1.4332

17. McCullough $\mathrm{H}$. The determination of ammonia in whole blood by a direct colorimetric method. Clin Chim Acta. 1967; 17(2):297-304. https:// doi.org/10.1016/0009-8981(67)90133-7

18. Miller GL. Use of dinitrosalicylic acid reagent for determination of reducing sugar. Anal Biochem. 1959; 31(3):426-428. https:// pubs.acs.org/doi/abs/10.1021/ac60147a030

19. SAS. Statistical Analisys Sofware, SAS/STAT. Version 9.33 Edition. Cary (NC): SAS institute Inc; 2011.

20. Elghandour MMY, Kholif AE, Lopez S, Mendoza GD, Odongo NE, and Salem AZM. In vitro gas, methane and carbon dioxide productions of high fibrous diet incubated with fecal inocula from horses fed live yeasts in response to the supplementation with different yeast additives. J Equine Vet Sci. 2016; 38:64-71. DOI: http://dx.doi. org/10.1016/j.jevs.2015.12.010

21. Zicarelli F, Calabrò S, Cutrignelli MI, Infascelli $F$, Tudisco $R$, and Bovera F. In vitro fermentation characteristics of diets with different forage/concentrate ratios: comparison of rumen and faecal inocula. J Sci Food Agric. 2011; 91(7):1213-1221. DOI: https://doi.org/10.1002/jsfa.4302

22. Duarte A, Luna RS, Starns HD, Weckerly FW. Intraspecific scaling of rumen-reticulum fill might depend on dietary fiber. Am Midl Nat. 2014; 172(2):329-337. https://doi. org/10.1674/0003-0031-172.2.329 
23. Thurston B, Dawson KA, Strobel $\mathrm{HJ}$. Pentose utilization by the ruminal bacterium Ruminococcus albus. Appl Environ Microbiol. 1994; 60(4):1087-1092. https://www.ncbi. nlm.nih.gov/pubmed/8017905

24. Russell JB, O'Connor JD, Fox DG, Van Soest PJ, Sniffen CJ. A net carbohydrate and protein system for evaluating cattle diets: I. Ruminal fermentation. J Anim Sci. 1992; 70(11):3551-3561. https://doi. org/10.2527/1992.70113551x

25. Carro MD, López S, Valdés C, Ranilla MJ. Effect of nitrogen supplementation on the in vitro rumen fermentation of nitrogen deficient forages. Arch Zootec. 1999; 48(183):295306. http://www.uco.es/organiza/servicios/ publica/az/php/img/web/02 032405 carro. pdf

26. Rodríguez MC, Aguirre E, Salvador F, Ruiz O, Arzola C, La OO, Villalobos C. Producción de gas, ácidos grasos volátiles y nitrógeno amoniacal in vitro con dietas basadas en pasto seco. Revista Cubana de Ciencia Agrícola. 2010; 44(3):251-259. http://www.redalyc. org/pdf/1930/193015664007.pdf
27. Chandrasekharaiah $M$, Thulasi A, Suresh KP, Sampath KT. Rumen degradable nitrogen requirements for optimum microbial protein synthesis and nutrient utilization in sheep fed on finger millet straw (Eleucine coracana) based diet. Anim Feed Sci Technol. 2011; 163(2-4):130-135. DOI: https://doi. org/10.1016/j.anifeedsci.2010.10.015

28. Chanthakhoun V, Wanapat $M$, Kongmun $P$, Cherdthong A. Comparison of ruminal fermentation characteristics and microbial population in swamp buffalo and cattle. Livest Sci. 2012; 144(3):172-176. DOI: https://doi. org/10.1016/j.livsci.2011.11.011

29. Otajevwo FD, Aluyi HSA. Cultural conditions necessary for optimal cellulase yield by cellulolytic bacterial organisms as they relate to residual sugars released in broth medium. Mod Appl Sci. 2011; 5(3):141-151. https:// doi.org/10.5539/mas.v5n3p141

30. Galindo J, Marrero Y, González N, Aldama AI. Caracterización de la actividad celulolítica en el líquido de rumen filtrado. Rev Cub Cienc Agríc. 2004; 38(3):259-263. http://www. redalyc.org/pdf/1930/193017849006.pdf 